\title{
DE MOCHILA NAS COSTAS E COM O "PÉ NA ESTRADA": A MOBILIDADE PENDULAR DE ESTUDANTES DE NÍVEL SUPERIOR DA REGIÃO METROPOLITANA DA BAIXADA SANTISTA ${ }^{1}$
}

\author{
William de Mendonça Lima ${ }^{2}$ \\ Luiz Antonio Chaves de Farias ${ }^{3}$
}

\section{INTRODUÇÃO}

Ao mesmo tempo em que a Região Metropolitana da Baixada Santista (RMBS), relativamente a outras Regiões Metropolitanas (RMs) do Estado de São Paulo, possui um amplo e diversificado mercado de trabalho, fomentado, principalmente, pelas atividades, portuárias, industriais e de turismo. No entanto, no campo da educação de nível superior ainda se recinte de ofertas mais vastas.

Esse quadro se repercute em complementariedades socioespaciais estabelecidas intra e interregionalmente, sob o ponto de vista da mobilidade pendular para fins de estudo na região. Em outras palavras, há um grande contingente populacional, mais de $42 \%$ de que cursava o nível superior em 2010, que necessitava deslocar-se para outros municípios no sentido de acessar este serviço. Tais deslocamentos aconteciam tanto nos limites da RMBS - onde quase totalidade desse volume se destinava para Santos - como para outras regiões metropolitanas, como a Região Metropolitana de São Paulo (RMSP) que recebia um volume considerável desses fluxos, principalmente dos municípios mais afastados do core metropolitano (Bertioga, Peruíbe, Itanhaém e Mongaguá).

Em face do quadro descrito acima, o objetivo proposto aqui é analisar os movimentos pendulares para fins de estudo na RMBS, sob o ponto de vista de sua espacialidade, condicionantes e consequências sociais para quem o faz ou não. No sentido de viabilizar essa empreitada foram utilizadas as seguintes fontes de dados: o Censo Demográfico de 2010, a pesquisa de vulnerabilidade (pesquisa amostral representativa para a RMBS realizada em 2007 pelo NEPO) e o Censo da Educação Superior de 2010.

\footnotetext{
1 Este artigo foi financiado pelo Centro de Estudos da Metrópole (CEBRAP, USP), processo $\mathrm{n}^{\circ}$ 2013/07616-7. Fundação de Amparo à Pesquisa do Estado de São Paulo (FAPESP). As opiniões, hipóteses e conclusões ou recomendações expressas são de responsabilidade do(s) autor(es) e não necessariamente refletem a visão da FAPESP

${ }^{2}$ Doutorando do Programa de Pós-graduação em Demografia do NEPO/ IFCH/ UNICAMP.

${ }^{3}$ Doutorando do Programa de Pós-graduação em Demografia da NEPO/ IFCH/ UNICAMP.
} 
Antecede à apresentação destes resultados, encontrados na última parte deste artigo, duas importantes seções: a primeira, que traz uma discussão teórica acerca da definição e dos diferentes enfoques sobre mobilidade pendular, bem como sua relevância na construção do espaço de vida dos indivíduos a partir das relações espaciais desenvolvidas cotidianamente. Na segunda seção foi desenvolvida uma discussão acerca da urbanização e dinâmica sociodemográfica da RMBS, aspectos que auxiliam na compreensão dos deslocamentos pendulares com fins de estudos na região.

\section{Mobilidade pendular: diferentes perspectivas}

Os movimentos pendulares se caracterizam enquanto deslocamento de um indivíduo com propósito de trabalho ou estudo para outro município diferente do que reside (SOBREIRA, 2007). No entanto, esta é uma definição adotada por questões operacionais, já que nos Censos Demográficos (de 1980, 2000 e 2010) ela é captada através do quesito de local de trabalho ou estudo e código do município. Todavia, em outras fontes (como pesquisas do tipo Origem/Destino) os deslocamentos ocorridos em âmbitos menores que o limite municipal também são captados (SOBREIRA, 2007). Assim, considerando o seu caráter conceitual, a mobilidade pendular se configura enquanto deslocamentos realizados pelo indivíduo para realizar atos de sua vida cotidiana, como trabalho, compras, lazer e estudos (BRANCO et al., 2005).

Alguns estudos se destacam por sua profundidade na discussão sobre mobilidade pendular. A esse respeito se sobressaem os trabalhos de Magalhães et al. (2006) e Marandola Jr. (2006), onde estes autores mencionam o movimento pendular como elemento importante na construção do espaço de vida dos indivíduos através das relações espaciais desenvolvidas cotidianamente.

Este conceito (espaço de vida), é desenvolvido na Geografia do espaço vivido de Armand Fremont (1970), relaciona espaço de vida à biografia da pessoa, como consequência do levantamento de lugares frequentados por ela ao longo de sua vida. Posteriormente, é adaptado e utilizado na Demografia por Daniel Courgeau (1988), com propósito de intensificar as investigações sobre mobilidade espacial da população. Nesse âmbito, os deslocamentos pendulares seria uma importante intermediação entre o espaço de vida e o espaço urbano.

Nesse sentido confluem os trabalhos de Marandola Jr. (2006) e Lima (2015). O primeiro autor desenvolve uma reflexão acerca dos impactos dos deslocamentos 
pendulares sobre a vida das pessoas, no sentido da exposição a riscos e potencialização da vulnerabilidade. O segundo analisa os efeitos desses deslocamentos, com fins de estudos, na vida escolar de estudantes da educação básica.

Há uma grande variedade, na literatura nacional e internacional, de enfoques sobre estudos de mobilidade pendular. Uma relação entre estes deslocamentos e desigualdade/ segregação socioespacial é desenvolvida nos trabalhos de Lago (2000), Cunha et al. (2005) e Caiado (2005). Este último autor indica que a relação entre mobilidade e segregação se estabelece quando os grupos de menor poder aquisitivo e poder político, que residem em áreas de acesso restrito à infraestrutura urbana e serviços básicos, precisam se submeter a deslocamentos diários para acessar o mercado de trabalho, os serviços de educação e saúde etc.

Por sua vez, a relação entre migração intrametropolitana e deslocamentos pendulares, outro exemplo de enfoque sobre mobilidade pendular, se dá através da complementariedade destes deslocamentos com este tipo de migração (PEREIRA, 2008). Isso ficou evidente no trabalho desenvolvido por Cunha (1994) para a Região Metropolitana de São Paulo (RMSP), onde este autor evidencia as mudanças do padrão de mobilidade espacial da população e do padrão espacial metropolitano a partir da década de 1970.

Análise semelhante foi desenvolvida por Pereira (2008), em 2000 para a Região Metropolitana de Campinas (RMC), onde em seus resultados verifica que uma considerável proporção de migrantes intrametropolitanos $(26,1 \%)$ também realizavam deslocamentos pendulares. Esses resultados mostram que uma grande quantidade de migrantes intrametropolitanos ainda mantém vínculo com o município de origem, no que diz respeito ao trabalho e/ou estudos através dos deslocamentos pendulares.

Nesses dois casos ressaltou-se a hipótese de que as pessoas comutam ${ }^{4}$, cotidianamente, porque migram. Contudo, também há casos em que as pessoas não migram porque comutam, ou seja, a comutação seria uma alternativa para as pessoas não migrarem. A esse respeito, Pereira (2008: 19) afirma que,

[...] diante das opções de migrar ou da possibilidade de comutar (viabilizada por determinadas condições de infra-estrutura e acesso aos meios de transporte e custos aceitáveis de deslocamento) essas pessoas preferem comutar. A possibilidade de recorrer aos deslocamentos pendulares se faria,

\footnotetext{
${ }^{4}$ Neste artigo, o termo "comutadores" - derivado do inglês: commuting (comutação) - refere-se aos indivíduos inseridos em um processo comutação (pendularidade ou movimento pendular) onde os limites administrativos de seus respectivos municípios de residência são transpassados em função de suas necessidades (lazer, trabalho, estudos etc.).
} 
então, como um fator de retenção de população diminuindo os fluxos migratórios. Ao contrário daquela relação entre pendularidade e migração intrametropolitana, que afirma que as pessoas comutam porque migraram, poderia-se pensar que algumas pessoas não migram justamente porque comutam, ou seja, algumas pessoas comutam justamente para não ter que migrar.

Em outro ponto de vista, Jun \& Bae (2000) analisam a relação entre mobilidade pendular e custos monetários para os indivíduos inseridos nesses deslocamentos em Seul, na Coreia do Sul. Entretanto, a distância percorrida e o tempo despendido nesses deslocamentos, os custos envolvidos vão além do aspecto monetário. Segundo Harvey (1992: 53),

[...] o preço social que a gente deve pagar para ter acesso a certos serviços é algo que pode variar desde o simples custo direto do transporte ao preço psicológico e emocional imposto a um indivíduo que opõe uma intensa resistência em fazer algo [...]

Além dos custos pessoais enfrentado pelos comutadores - muito complexo de mensurar e apreender - também há gastos públicos com construção e manutenção de infraestrutura de serviços (como transporte público) (PEREIRA, 2008).

Todavia, Castells $(1975)^{5}$, menciona a necessidade desses deslocamentos sob o ponto de vista da integração entre os municípios de uma localidade (região metropolitana, macrometrópole etc). Ele afirma que,

[...] quanto mais as unidades urbanas aumentam de dimensão e complexidade mais as relações internas tomam importância, pois nenhum setor pode bastarse a si mesmo e a dinâmica do aglomerado só se realiza ao nível de seu conjunto (CASTELLS, 1975 :237)

Nesse sentido Fusco e Ojima (2017: 258), em seu estudo sobre o crescimento do volume dos deslocamentos pendulares com fins de estudos, a partir da integração do ensino superior no interior de Pernambuco, mencionam dois aspectos intrínsecos a este fenômeno: i) os efeitos diretos que esses deslocamentos de pessoas, entre os municípios, podem trazer para os serviços públicos (setor de transportes, até o atendimento de saúde e mão de obra etc.) assim como, associados a esses deslocamentos estão as ii) novas dinâmicas regionais, isto é,

[...] empregos indiretos decorrentes da dinamização da economia regional/local, como restaurantes, lanchonetes, papelarias, entre outros tantos. Ademais, a provável migração de mão de obra qualificada, qual seja, do corpo docente que atua nos campi, contribui para a criação e satisfação de demanda de serviços diferenciados.

\footnotetext{
${ }^{5}$ Citado por Pereira (2008:9)
} 
Apesar da diversidade nos trabalhos sobre mobilidade pendular, apresentada aqui, são poucos os casos em que este fenômeno é o objeto central dos estudos, na maioria das vezes, estes trabalhos têm como principal objeto de análise outros elementos, e enxergam na mobilidade pendular um tema secundário, mas de grande importância (PEREIRA, 2008).

Nesses estudos, geralmente, percebe-se uma grande quantidade de produções que analisam a presença deste fenômeno principalmente com fins de trabalho e pouco tem sido produzido para estes deslocamentos com fins de estudos. Contudo, um dos esforços realizados aqui é o de mostrar a relevância desta última categoria de deslocamentos e suas implicações no âmbito sociodemográfico.

\section{A trajetória recente da Baixada Santista: urbanização e dinâmica sociodemográfica}

A RMBS é composta por nove municípios: Bertioga, Cubatão, Guarujá, Itanhaém, Mongaguá. Peruíbe, Praia Grande, Santos e São Vicente (Mapa 1). Com cerca de 1,65 milhões de habitantes em 2010 (segundo o Censo do IBGE), foi instituída pela Lei Complementar Estadual no 815, em 30 de julho de 1996 (a primeira criada no Brasil após a Constituição de 1988).

Mapa 1 - Localização da área de estudo

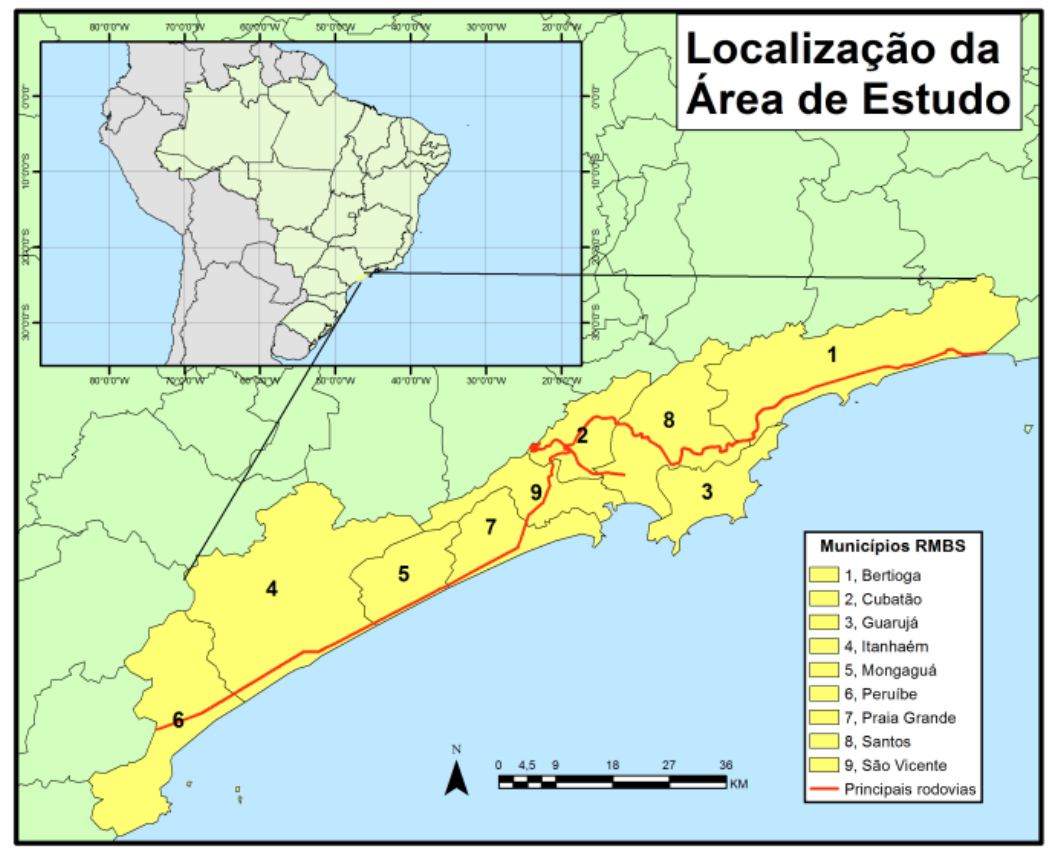

Elaboração: Autores 
É uma das áreas de ocupação urbana mais antiga do território nacional, datada do século XVI. Essa urbanização precoce, no entanto, aufere uma intensificação na virada do século XIX para o XX, com o protagonismo do Porto de Santos no ciclo agroexportador do café, e seus efeitos indutores para o território regional.

Esse quadro se intensifica ainda mais com a instalação do polo industrial de Cubatão, em finais dos anos 40. Aliado às já vastas ofertas de emprego propiciadas pelas atividades portuárias e de turismo de veraneio, o mercado de trabalho da região apresenta um aumento vertiginoso. Não por acaso, é partir desse período até os anos 80, que se registram a maiores taxas de crescimento populacional, os maiores volumes de fluxos migratórios destinados à região, e mesmo, uma intensificação precoce do processo de metropolização, em relação a outras aglomerações urbanas. De acordo com Jakob (2003), as taxas de crescimentos médias anuais eram de: 1950/60 - 4,54\% a.a.; 1960/70 - 4,59\% a.a.; 1970/1980 - 3,94\% a.a..

Os anos 80 e 90 representaram para a Baixada Santista um turning point com relação à dinâmica econômica (COLANTONIO, 2009) seguida até então. Isso porque, com a crise fiscal do Estado Brasileiro, os investimentos estatais tão importantes para a estruturação da região, foram reduzidos drasticamente. Assim, o mercado de trabalho regional observou uma intensa retração, com repercussões diretas sobre o aumento da pobreza e segregação residencial, que passam a ser uma das principais marcas do processo de metropolização regional.

Para a década de 90 em específico, segundo Dedecca (2009), as causas para o quadro descrito acima se relacionam ao fato de que o período comportou significativas mudanças nas relações de produção. A financeirização da economia, a reestruturação dos sistemas de produção e a desregulamentação, proporcionaram uma redução expressiva de trabalhadores em muitos ramos de atividade econômica.

Além disso, a maior concorrência dos mercados obrigando as empresas a buscar incessantemente ganhos de produtividade, colocou a existência de Centros de Pesquisa e tecnologia, assim como, de Instituições de Ensino Superior de excelência entre os elementos mais importantes das Condições Gerais de Produção, responsáveis por viabilizar a alocação de determinados tipos atividades econômicas nos territórios.

Dentro desse novo contexto produtivo, verificou-se um aprofundamento da dinâmica de perda de importância relativa da RMBS em relação a outras regiões do interior paulista. No bojo do processo de desconcentração industrial paulista, os investimentos preferencialmente se direcionaram para outras aglomerações urbano- 
regionais próximas à capital - Campinas, São José dos Campos e Sorocaba, principalmente - que continham vantagens indiscutíveis em relação à Baixada Santista. Além da proximidade com a capital e seu mercado consumidor, essas regiões são dotadas de boa infraestrutura e principalmente de centros de pesquisa e universitários de qualidade, aspecto último inexistente na RMBS (COLANTONIO, 2009).

Com efeito, no âmbito intrarregional, o empobrecimento da região trabalhou por intensificar o processo de segregação residencial, induzindo/forçando determinados grupos sociais a migrar do núcleo para os municípios periféricos do litoral sul (JAKOB, 2003). Além disso, é verificado um espraiamento da urbanização para os municípios do litoral sul e norte.

A partir desse último processo se verificou que a metropolização da Baixada Santista assumiu uma característica peculiar se comparada a outras realidades metropolitanas, em virtude da proximidade geográfica de algumas municipalidades com a RMSP. Assim, observou-se a formação de "periferias com dois centros", já que muitas demandas que, potencialmente, poderiam ser satisfeitas no núcleo urbanoregional, acabam por serem direcionadas a Grande São Paulo. Fenômeno que pode ser melhor percebido para os municípios mais periféricos geograficamente ao core metropolitano, capitaneado pelo município de Santos.

Concorre para fomentar a dinâmica em questão, primeiramente, o fato da desconcentração da ocupação da RMBS, não ter sido acompanhada de uma desconcentração econômica. Levando a um contingente cada vez maior de indivíduos a realizarem deslocamentos pendulares na região (CUNHA et. al., 2013).

Por sua vez, a melhoria do sistema viário que liga as duas metrópoles (duplicação das rodovias Padre Manoel da Nobrega e Cônego Domenico Rangoni e a inauguração da pista do Sul da Rodovia dos Imigrantes em 2002), propiciou deslocamentos rodoviários mais rápidos entre as mesmas. Ademais, outro condicionante para maneira como se deu essa articulação intra e interregional, é a forma longitudinal das áreas passíveis de ocupação. Logo, os municípios mais periféricos geograficamente acabam distando equivalentemente tanto do núcleo da Ilha de São Vicente quanto das localidades mais ao sul da RMSP.

Dessa forma, o tempo de deslocamento entre alguns municípios do litoral sul e o congestionado centro, comercial e de serviços, de Santos é equivalente ao que é gasto para se chegar a São Paulo pelo moderno sistema viário Anchieta-Imigrantes. Tal realidade pode ser bem vista pelos dados da tabela 1 , onde o tempo de deslocamento 
dos municípios mais distantes como Bertioga e Peruíbe, é praticamente o mesmo, seja para Santos, seja para RMSP (referenciada nos bairros mais ao sul do município de São Paulo, como Jabaquara).

Tabela 1 - Tempo de deslocamento pelo modal rodoviário de carro e distâncias entre os municípios da RMBS e as principais centralidades regionais (municípios Santos e a RMSP)

\begin{tabular}{l|cc|cc}
\hline \multirow{2}{*}{$\begin{array}{c}\text { Local de } \\
\text { origem }\end{array}$} & \multicolumn{2}{c|}{ Santos } & \multicolumn{2}{c}{ RMSP } \\
\cline { 2 - 5 } & Tempo & Distancia & Tempo & Distancia \\
\hline Bertioga* & $1 \mathrm{~h} 15$ & $74 \mathrm{~km}$ & $1 \mathrm{~h} 30$ & $110 \mathrm{~km}$ \\
Cubatão & 30 minutos & $18 \mathrm{~km}$ & 50 minutos & $50 \mathrm{~km}$ \\
Guarujá & $1 \mathrm{~h}$ & $11 \mathrm{~km}$ & $1 \mathrm{~h} 15$ & $86 \mathrm{~km}$ \\
Itanhaém & $1 \mathrm{~h}$ & $55 \mathrm{~km}$ & $1 \mathrm{~h} 20$ & $101 \mathrm{~km}$ \\
Mongaguá & $1 \mathrm{~h}$ & $44 \mathrm{~km}$ & $1 \mathrm{~h} 15$ & $90 \mathrm{~km}$ \\
Peruíbe & $1 \mathrm{~h} 25$ & $83 \mathrm{~km}$ & $1 \mathrm{~h} 50$ & $128 \mathrm{~km}$ \\
Praia Grande & 30 minutos & $13 \mathrm{~km}$ & $1 \mathrm{~h}$ & $65 \mathrm{~km}$ \\
São Vicente & 20 minutos & $7 \mathrm{~km}$ & 52 minutos & $60 \mathrm{~km}$ \\
\hline
\end{tabular}

- Tempo e distância para Mogi das Cruzes: 1 h e 54 km Fonte: Google Maps. Elaboração: autores.

Dado o quadro de constituição do espaço urbano da região esboçado acima e de sua inserção socioespacial em um contexto regional mais amplo, como o da Macrometrópole Paulista ${ }^{6}$ Empreende-se uma leitura das complementariedades socioespaciais estabelecidas intra e interregionalmente sob o ponto de vista da mobilidade pendular por motivos de estudo.

\section{A mobilidade pendular para fins de estudo na RMBS}

\subsection{Fontes de dados}

Antes de apresentar os principais resultados encontrados será mencionado, brevemente, algumas características, potencialidades e limitações, das fontes de dados exploradas que viabilizaram o desenvolvimento desse trabalho: o Censo Demográfico de 2010, o Censo do Ensino Superior de 2010 e a Pesquisa de Vulnerabilidade de 2007.

6 A "Macrometrópole Paulista", assim definida pela EMPLASA (2012), envolve 168 municípios distribuídos entre as quatro tradicionais Regiões Metropolitanas oficiais do Estado de São Paulo, além de municípios situados nas regiões de influencia de Piracicaba, Sorocaba, Jundiaí, São Roque e Bragança Paulista. 
A primeira fonte de dados mencionada (o Censo Demográfico) é bem conhecida e explorada nos estudos sobre o tema questão. Contudo, convém destacar uma evolução para o quesito de pendularidade presente no levantado de 2010 em relação aos anteriores: a separação dos deslocamentos pendulares com fins de estudos daqueles com fins de trabalho. Isso foi fundamental para distinguir essas duas categorias de deslocamento e ampliar as possibilidades analíticas do fenômeno, conforme feito aqui.

O Censo do Ensino Superior, por sua vez, é um levantamento de caráter nacional realizado anualmente pela Diretoria de Estatísticas Educacionais em todas as Instituições de Educação Superior (IES), públicas e privadas, do país (INEP, 2011). A partir dessa pesquisa foi possível obter informações sobre a quantidade de IES por município e suas respectivas categorias administrativas (pública: estadual, municipal ou federal e privada: com/sem fins lucrativos).

Por fim, a pesquisa de vulnerabilidade de 2007 é uma pesquisa amostral coordenada pelo Núcleo de Estudos de População Elza Berquó (NEPO), desenvolvida no âmbito do projeto "Dinâmica Intrametropolitana e Vulnerabilidade nas Metrópoles do Interior Paulista: Campinas e Santos" de mesmo ano mencionado. Para a RMBS, o levantamento abrangeu cerca de 1600 domicílios urbanos, envolvendo cerca de 4800 pessoas. Em termos de conteúdo, incluiu temas relacionados à(s): características do Domicílio, do Entorno e Percepção Ambiental; Características Sociodemográficas da População; Trabalho e Rendimentos; Saúde; Família e Comunidade; Mobilidade Espacial da População; e, Educação. Estas duas últimas temáticas foram bem exploradas aqui e viabilizou achados importantes como o tempo de deslocamento gasto no deslocamento para estudos (variável não presente no Censo Demográfico) e a seletividade socioeconômica dos comutadores na região.

Desse modo, a análise dessas três fontes de dados foi fundamental para construir resultados consistentes sobre os deslocamentos pendulares, com fins de estudos, na RMBS, conforme segue nos tópicos seguintes.

\subsection{Dimensionando a oferta e a demanda do ensino superior na RMBS}

A análise da distribuição da oferta de vagas em instituições de ensino superior na RMBS (tabela 2) confirma a hipótese levantada pelo trabalho em relação à distribuição desfavorável a região das IES entre diferentes RM's da macrometrópole paulista. De fato, a RMBS possuía apenas 19 IES em 2010. Por outro lado, a RMSP apresentava 
cerca de 11 vezes mais IES, enquanto que, tanto a RMC quanto a RMVPL, apresentavam praticamente o dobro de sua oferta.

Entre os municípios da RMBS, esse panorama de desigualdade da distribuição da IES não foi muito diferente, já que, Santos, município polo da região, concentrava quase a metade da oferta de estabelecimentos. $\mathrm{O}$ resto se distribuiu nos municípios de entorno.

Tabela 2 - Instituições de ensino superior por RMs do estado de São Paulo e municípios da RMBS. 2010.

\begin{tabular}{c|c|c|c}
\hline \multicolumn{2}{c|}{ Por RMs } & \multicolumn{2}{c}{ Por Municípios da RMBS } \\
\hline RMBS & 19 & BERTIOGA & 1 \\
RMSP & 219 & CUBATÃo & 0 \\
RMC & 35 & GUARUJA & 2 \\
RMVPLN & 36 & ITANHAEM & 1 \\
Total & 309 & MONGAGUÁ & 0 \\
& & PERUIBE & 1 \\
& & PRAIA GRANDE & 3 \\
& & SANTOS & 9 \\
& & SAO VICENTE & 2 \\
\end{tabular}

FONTE: INEP. Censo da Educação Superior 2010. Tabulações especiais NEPO.

Em relação à categoria administrativa da IES (tabela 3), que para a realidade brasileira pode ser utilizado enquanto proxy da qualidade do ensino ofertado na maioria dos casos, verifica-se o mesmo quadro de desigualdade observado anteriormente. Isso porque, a oferta de IES de cunho público na RMBS, se restringe a dois estabelecimentos, com status de filial. Diferente de outras RMs que apresentam uma oferta mais ampla, cujos números chegam 20 IES públicas, como no caso da RMSP.

Tabela 3 - Instituições de ensino superior por categoria administrativa. RMBS. 2010.

\begin{tabular}{c|c|c|c|c|c|c}
\hline \multirow{2}{*}{ Região } & \multicolumn{5}{|c|}{ Categoria administrativa da Instituição de Ensino } & \multirow{2}{*}{ Superior } \\
\cline { 2 - 5 } & $\begin{array}{c}\text { Pública } \\
\text { Estadual }\end{array}$ & $\begin{array}{c}\text { Pública } \\
\text { Federal }\end{array}$ & $\begin{array}{c}\text { Pública } \\
\text { Municipal }\end{array}$ & $\begin{array}{c}\text { Privada } \\
\text { com fins } \\
\text { lucrativos }\end{array}$ & $\begin{array}{c}\text { Privada } \\
\text { sem fins } \\
\text { lucrativos }\end{array}$ & \\
\hline RMBS & 2 & 0 & 0 & 8 & 9 & 19 \\
RMSP & 14 & 3 & 3 & 78 & 121 & 219 \\
RMC & 3 & 0 & 0 & 16 & 16 & 35 \\
RMVPLN & 5 & 1 & 2 & 16 & 12 & 36 \\
\hline
\end{tabular}


FONTE: INEP. Censo da Educação Superior 2010. Tabulações especiais NEPO.

O breve quadro descrito acima, além de ilustrar o, já mencionado, quadro de esvaziamento tecnológico e de pesquisa sofrido pela Baixada Santista (COLANTONIO, 2009), tem desdobramentos sobre a demanda reprimida existente na região por vagas em IES. A principal alternativa tomada pelos indivíduos é deslocar-se cotidianamente para outros municípios onde a mesma possa ser suprida, ou até mesmo migrar para outras áreas, quando se tem condições de fazer e a comutação não é possível.

A mobilidade pendular com fins de estudos se confirmou nos dados (tabela 4), tendo em vista que a RMBS, relativamente a outras regiões, apresentou o maior percentual de estudantes matriculados no ensino superior que realizavam deslocamento pendular para acessar a IES, pouco mais de 44\%. Quase o dobro do verificado para RMSP $(23,35 \%)$, onde se tem a maior oferta, muito acima da média da UF de São Paulo (31,7\%), e mesmo, do Brasil (29,64\%).

Da mesma forma, quando se olha para os municípios da RMBS, nota-se que praticamente em todos eles a maior parte das pessoas matriculadas em IES, se deslocam para outro município para estudar. Mesmo naqueles mais distantes, como Peruíbe e Itanhaém, nos quais, muitas das vezes, o deslocamento pode durar mais de duas horas para se acessar as poucas instituições do core metropolitano. A exceção fica por conta de Santos, onde a maior parte dos estudantes estudam no próprio município.

Tabela 4 - População residente matriculada no ensino superior, por local de estudo, segundo município/região de residência. 2010.

\begin{tabular}{l|c|c|c|c}
\hline \multirow{2}{*}{$\begin{array}{c}\text { Município/Região } \\
\text { de residência }\end{array}$} & $\begin{array}{c}\text { Em outro } \\
\text { município }\end{array}$ & $\begin{array}{c}\text { Em país } \\
\text { estrangeiro }\end{array}$ & $\begin{array}{c}\text { Neste } \\
\text { município }\end{array}$ & \multirow{2}{*}{ Total geral } \\
\cline { 2 - 3 } BERTIOGA & 54,71 & 0,83 & 44,46 & 839 \\
CUBATÃo & 85,71 & 0,00 & 14,29 & 3114 \\
GUARUJÁ & 38,24 & 0,63 & 61,13 & 6820 \\
ITANHAÉM & 59,71 & 0,00 & 40,29 & 1983 \\
MONGAGUÁ & 87,53 & 0,00 & 12,47 & 850 \\
PERUÍBE & 70,78 & 0,00 & 29,22 & 1160 \\
PRAIA GRANDE & 65,92 & 0,00 & 34,08 & 6811 \\
SANTOS & 17,08 & 0,20 & 82,71 & 22197 \\
SÃO VICENTE & 72,70 & 0,00 & 27,30 & 9143 \\
\hline RMBS & 44,24 & 0,18 & 55,58 & 52918 \\
RMC & 37,05 & 0,11 & 62,84 & 135291 \\
RMSP & 23,35 & 0,38 & 76,26 & 979353 \\
UF SP & 31,70 & 0,26 & 68,05 & 1802778 \\
Brasil & 29,64 & 0,28 & 70,09 & 7119162 \\
\hline
\end{tabular}


FONTE: FIBGE. Microdados da amostra do Censo Demográfico 2010. Tabulações especiais NEPO.

Ao se contrapor o cenário esboçado acima com os deslocamentos pendulares para trabalho (tabela 5), percebe-se que apesar da crise econômica dos 80 e do ajuste fiscal da década de 90, que impactaram a oferta de empregos na região, o mercado de trabalho oferece oportunidades mais vastas de alocação no próprio município de residência. Isso porque, ainda que levemente mais elevado em relação às demais regiões consideradas, o percentual de pessoas que realizam deslocamento pendular para trabalho não ultrapassou 25\%. Valor relativamente próximo do aferido para as outras RMs consideradas, da UF de São Paulo e do Brasil.

Tabela 5 - População residente empregada, por local de trabalho, segundo município/região de residência. 2010.

\begin{tabular}{l|cccc|c}
\hline \multirow{2}{*}{$\begin{array}{c}\text { Município/Região } \\
\text { de residência }\end{array}$} & $\begin{array}{c}\text { Em outro } \\
\text { município }\end{array}$ & $\begin{array}{c}\text { Em país } \\
\text { estrangeiro }\end{array}$ & $\begin{array}{c}\text { Neste } \\
\text { município }\end{array}$ & \multirow{2}{*}{ Total geral } \\
\cline { 2 - 4 } BERTIOGA & 5,10 & 0,03 & 94,87 & 23467 \\
CUBATÃo & 20,43 & 0,00 & 79,57 & 50298 \\
GUARUJÁ & 17,22 & 0,03 & 82,75 & 128364 \\
ITANHAÉM & 12,27 & 0,00 & 87,73 & 36850 \\
MONGAGUÁ & 21,28 & 0,06 & 78,66 & 17821 \\
PERUÍBE & 10,18 & 0,00 & 89,82 & 25794 \\
PRAIA GRANDE & 28,05 & 0,04 & 71,91 & 114964 \\
SANTOS & 17,18 & 0,05 & 82,77 & 201100 \\
SÃO VICENTE & 50,10 & 0,04 & 49,86 & 147455 \\
\hline RMBS & 24,82 & 0,04 & 75,14 & 746112 \\
RMC & 20,23 & 0,03 & 79,74 & 1421373 \\
RMSP & 17,85 & 0,02 & 82,13 & 9479401 \\
UF SP & 16,02 & 0,02 & 83,96 & 20001271 \\
Brasil & 12,80 & 0,04 & 87,16 & 86353839 \\
\hline
\end{tabular}

FONTE: FIBGE. Microdados da amostra do Censo Demográfico 2010. Tabulações especiais NEPO

\subsection{Qual a orientação dos fluxos pendulares para estudo?}

No que se refere à orientação dos fluxos pendulares para estudo (tabela 6), conforme poderia se supor a partir do que foi apresentado acima, seu direcionamento foi áreas mais carentes na oferta de IES para áreas que concentram mais vagas. Assim sendo, no plano interregional, percebeu-se que a maior parte dos fluxos direcionava-se à própria RMBS. No entanto, parte significativa dos mesmos se destinavam à RMSP, 
quase $20 \%$. Em alguns casos, como o de Bertioga e Itanhaém, o valor ficou em torno de $25 \%$.

Para a realidade específica de Santos, dado o fato de o município concentrar a maior parte das oportunidades educacionais para o ensino superior da região, como se pode observar na tabela 4, maior parte das pessoas acessam a IES no próprio município. Logo, quem sai do município tende a procurar IES fora da RMBS, explicando-se o valor mais alto, de cerca de 57\%, que se dirigem à RMSP.

Desse modo, a complementariedade socioespacial entre a RMSP e RMBS (CUNHA et. al., 2013), ficou bem definida para os fluxos pendulares para estudo. Em alguns casos, como o de Praia Grande, às vezes, mostra-se mais vantajoso estudar no município de São Paulo, no mesmo tempo, em que acessaria uma IES em Santos.

Dentro da RMBS, o destino mais procurado é o município polo, com valores que, em algumas situações, ultrapassam mais de 90\%. Nesse caso, a fricção imposta pela distância e seus custos socioeconômico, parece ser condicionante para os valores mais reduzidos registrados para os municípios mais distantes de Santos, como Bertioga, Mongaguá, Itanhaém e Peruíbe.

Tabela 6 - População residente matriculada no ensino superior que realizava deslocamento pendular, por região/município de estudo, segundo município de residência. RMBS. 2010.

\begin{tabular}{|c|c|c|c|c|c|c|c|c|c|c|}
\hline \multirow[b]{2}{*}{$\begin{array}{l}\text { MUNICIPIO DE } \\
\text { RESIDÊNCLA }\end{array}$} & \multicolumn{10}{|c|}{ MUNICIPIO DE ESTUDO } \\
\hline & BERTIOGA & CUBATÃo & GUARUJÁ & ITANHAÉM & MONGAGUÁ & PERUIBEE & $\begin{array}{c}\text { PRAIA } \\
\text { GRANDE }\end{array}$ & SANTOS & $\begin{array}{c}\text { SÃo } \\
\text { VICENTE }\end{array}$ & \multirow[t]{2}{*}{$\begin{array}{l}\text { TOTAL } \\
\text { RMBS }\end{array}$} \\
\hline & \multicolumn{9}{|l|}{$\%$} & \\
\hline BERTIOGA & 0,0 & 4,2 & 34,7 & 0,0 & 0,0 & 0,0 & 0,0 & 61,1 & 0,0 & 311 \\
\hline CUBATÃo & 0,0 & 0,0 & 0,9 & 0,0 & 0,0 & 0,0 & 0,7 & 94,3 & 4,2 & 2454 \\
\hline GUARUJÁ & 0,0 & 1,1 & 0,0 & 0,0 & 0,0 & 0,0 & 0,0 & 96,1 & 2,8 & 2180 \\
\hline ITANHAÉM & 0,0 & 0,0 & 2,7 & 0,0 & 1,4 & 1,4 & 11,5 & 80,7 & 2,2 & 768 \\
\hline MONGAGUÁ & 0,0 & 0,0 & 0,0 & 9,2 & 0,0 & 0,0 & 10,2 & 75,1 & 5,5 & 586 \\
\hline PERUIBBE & 0,0 & 0,0 & 0,0 & 9,7 & 1,8 & 0,0 & 1,4 & 87,1 & 0,0 & 496 \\
\hline PRAIA GRANDE & 0,0 & 0,6 & 0,0 & 0,2 & 0,0 & 0,0 & 0,0 & 90,0 & 9,3 & 3631 \\
\hline SANTOS & 1,1 & 17,6 & 17,0 & 0,0 & 0,0 & 0,0 & 12,4 & 0,0 & 51,8 & 845 \\
\hline SÃO VICENTE & 0,0 & 1,4 & 0,0 & 0,0 & 0,0 & 0,0 & 4,5 & 94,1 & 0,0 & 5983 \\
\hline \multirow[t]{3}{*}{ RMBS } & 0,1 & 1,7 & 1,7 & 0,6 & 0,1 & 0,1 & 3,2 & 86,9 & 5,7 & 17255 \\
\hline & \multicolumn{7}{|c|}{$\ldots$} & & & \\
\hline & & & & GLÃO DE ESTU & UDO & & & & & \\
\hline \multirow[t]{2}{*}{$\begin{array}{l}\text { MUNICÍPIO DE } \\
\text { RESDÊNCLA }\end{array}$} & \begin{tabular}{|c|} 
OUTROS \\
MUNICIPIOS \\
DA UF DE SP \\
\end{tabular} & OUTRA UF & RMSP & RMC & RMVPLN & RMBS & \multirow[t]{2}{*}{ TOTAL } & & & \\
\hline & \multicolumn{6}{|c|}{$\%$} & & & & \\
\hline BERTIOGA & 2,0 & 0,0 & 24,9 & 5,2 & 0,0 & 67,9 & 458 & & & \\
\hline CUBATÃo & 1,3 & 1,4 & 4,7 & 0,0 & 0,0 & 92,6 & 2649 & & & \\
\hline GUARUJÁ & 1,4 & 1,2 & 12,1 & 0,9 & 0,4 & 84,0 & 2594 & & & \\
\hline ITANHAÉM & 3,3 & 3,9 & 26,0 & 0,8 & 0,0 & 65,9 & 1165 & & & \\
\hline MONGAGUÁ & 0,0 & 2,4 & 18,9 & 0,0 & 0,0 & 78,7 & 745 & & & \\
\hline PERUIiBE & 8,5 & 8,5 & 22,5 & 0,0 & 0,0 & 60,4 & 821 & & & \\
\hline PRAIA GRANDE & 0,2 & 1,6 & 15,5 & 0,4 & 0,2 & 82,0 & 4427 & & & \\
\hline SANTOS & 8,4 & 7,8 & 57,2 & 3,5 & 0,8 & 22,3 & 3794 & & & \\
\hline SÃO VICENTE & 1,4 & 0,7 & 7,1 & 0,1 & 0,1 & 90,4 & 6615 & & & \\
\hline RMBS & 2,6 & 2,7 & 19,4 & 0,9 & 0,3 & 74,2 & 23270 & & & \\
\hline
\end{tabular}


Fonte: FIBGE. Microdados da amostra do Censo Demográfico 2010. Tabulações especiais NEPO

\subsection{Qual seu papel no espaço de vida dos indivíduos?}

Como pode ser visto, em trabalhos patentes sobre o tema da pendularidade (LAGO, 2008), realizar ou não deslocamento pendular não é um problema si, importando mais outros processos socioespaciais relacionados a esta categoria de mobilidade.

Para o nível do indivíduo, a abordagem do espaço de vida se mostra pertinente para o tipo de análise em questão. Pois conforme os resultados apresentados, a comutação com fins de estudos acontece intensamente na RMBS, e impacta no esgarçamento do espaço de vida.

Tal condição de deslocamento impõe custos sociais aos indivíduos submetidos a ela. Infelizmente, as diferentes dimensões desse custo social, não são captadas pelas pesquisas que se dispõe a abordar o fenômeno da pendularidade. Uma proxy interessante é o tempo de deslocamento, que passou a fazer parte do Censo Demográfico 2010, mas somente para o deslocamento pendular para trabalho. Felizmente, utilizando-se os microdados da pesquisa do Projeto Vulnerabilidade de 2007, pode-se avaliar a dimensão tempo (tabela 7).

Dessa maneira, de fato, quem acessa IES fora de seu município de residência, tende a gastar mais tempo se deslocando em relação a quem fica no mesmo município. Assim, a maior parte dos que não realizam deslocamento pendular (cerca de 53\%), dispende no máximo 30 minutos, entre a sua residência e a IES. Por sua vez, àqueles que realizam tal deslocamento para outros municípios, em sua maior parte $(34,7 \%)$, tende a gastar entre 30 e 45 minutos. Todavia, em municípios mais distantes, como Peruíbe, há casos em que os indivíduos gastam mais de duas horas de deslocamento.

Depreende-se, a partir, dessa variável sintomática que os custos sociais são, como já era esperado, maiores para quem realiza deslocamento pendular na RMBS. O tempo utilizado em deslocamento impõe menos horas disponíveis para os indivíduos dispender em outras atividades cotidianas, visando sua reprodução social e de sua família. Além disso, pode privá-lo de acessar outras dimensões da estrutura de oportunidades metropolitana, que não o estudo, como emprego, lazer, etc. 
Tabela 7 - População residente matriculada no ensino superior por tempo de deslocamento, segundo local da IES e do município de residência. RMBS. 2007.

\begin{tabular}{|c|c|c|c|c|c|c|c|c|c|c|}
\hline \multirow{3}{*}{$\begin{array}{c}\text { Local da } \\
\text { IES }\end{array}$} & \multirow{3}{*}{$\begin{array}{l}\text { Município } \\
\text { de } \\
\text { Residência }\end{array}$} & \multicolumn{8}{|c|}{ Tempo do deslocamento } & \multirow{3}{*}{ Total } \\
\hline & & $\begin{array}{c}\text { De } 0 \text { até } \\
15 \\
\text { minutos }\end{array}$ & $\begin{array}{c}\text { Mais de } \\
15 \text { até } 30 \\
\text { minutos }\end{array}$ & $\begin{array}{c}\text { Mais de } \\
30 \text { até } 45 \\
\text { minutos }\end{array}$ & $\begin{array}{c}\text { Mais de } \\
45 \\
\text { minutos } \\
\text { até } 1 \text { hora } \\
\end{array}$ & $\begin{array}{l}\text { Mais de } \\
1 \mathrm{~h} \text { até } \\
1: 30 \mathrm{~h}\end{array}$ & $\begin{array}{c}\text { Mais de } \\
1: 30 \mathrm{~h} \text { até } \\
2 \mathrm{~h}\end{array}$ & $\begin{array}{c}\text { Mais de } \\
2 \mathrm{~h} \text { até } \\
2: 30 \mathrm{~h}\end{array}$ & Não sabe & \\
\hline & & \multicolumn{8}{|c|}{$\%$} & \\
\hline \multirow{5}{*}{$\begin{array}{c}\text { Mesmo } \\
\text { município } \\
\text { de } \\
\text { residência }\end{array}$} & Guarujá & 0,0 & 41,9 & 58,1 & 0,0 & 0,0 & 0,0 & 0,0 & 0,0 & 1586 \\
\hline & $\begin{array}{c}\text { Praia } \\
\text { Grande }\end{array}$ & 58,0 & 21,8 & 20,2 & 0,0 & 0,0 & 0,0 & 0,0 & 0,0 & 1560 \\
\hline & Santos & 27,6 & 58,3 & 7,0 & 0,0 & 0,0 & 0,0 & 1,6 & 5,5 & 15995 \\
\hline & São Vicente & 37,4 & 43,5 & 19,1 & 0,0 & 0,0 & 0,0 & 0,0 & 0,0 & 1712 \\
\hline & Total & 28,6 & 53,1 & 12,8 & 0,0 & 0,0 & 0,0 & 1,2 & 4,2 & 20853 \\
\hline \multirow{8}{*}{$\begin{array}{c}\text { Outro } \\
\text { municipio }\end{array}$} & Cubatão & 0,0 & 100,0 & 0,0 & 0,0 & 0,0 & 0,0 & 0,0 & 0,0 & 270 \\
\hline & Guarujá & 0,0 & 0,0 & 67,0 & 0,0 & 33,0 & 0,0 & 0,0 & 0,0 & 503 \\
\hline & Itanhaém & 0,0 & 0,0 & 100,0 & 0,0 & 0,0 & 0,0 & 0,0 & 0,0 & 815 \\
\hline & Mongaguá & 0,0 & 33,5 & 33,1 & 0,0 & 33,5 & 0,0 & 0,0 & 0,0 & 1010 \\
\hline & Peruibe & 0,0 & 0,0 & 0,0 & 0,0 & 35,7 & 32,2 & 32,2 & 0,0 & 948 \\
\hline & $\begin{array}{c}\text { Praia } \\
\text { Grande }\end{array}$ & 7,0 & 19,9 & 28,4 & 15,4 & 17,4 & 0,0 & 5,5 & 6,5 & 4876 \\
\hline & São Vicente & 16,1 & 16,1 & 36,1 & 31,7 & 0,0 & 0,0 & 0,0 & 0,0 & 3427 \\
\hline & Total & 7,5 & 18,0 & 34,7 & 15,5 & 14,3 & 2,6 & 4,8 & 2,7 & 11849 \\
\hline
\end{tabular}

FONTE: NEPO. Microdados da amostra da Pesquisa de Campo do Projeto Vulnerabilidade 2007. Tabulações especiais (NEPO/UNICAMP)

\subsection{Há seletividade socioeconômica nos fluxos pendulares considerados?}

A análise da seletividade socioeconômica dos fluxos pendulares em questão se mostra importante, porque os processos que determinam a segregação residencial tendem a se refletir na seletividade dos grupos sociais que podem realizar o deslocamento pendular para estudo. Com isso, podem ou não acessar a estrutura de oportunidades de ensino, como exposto anteriormente, distribuída desigualmente na região.

Enfocando-se, portanto, a condição de pendularidade daqueles que cursavam o nível superior (tabela 8), por classes de rendimentos, nitidamente, percebe-se que aqueles que saiam de seu município para acessar uma IES se concentram nas classes mais altas de rendimento, se comparados àqueles que estudavam no mesmo município. Por exemplo, enquanto, aqueles, da faixa de 3 a 5 salários mínimos, que estudavam no mesmo município de residência, eram 13\%. Os deslocados pendulares, para mesma classe, eram representativos de quase $17 \%$. 
Ademais, nota-se também que para os municípios mais distantes (Bertioga, Peruíbe e Itanhaém), a seletividade por rendimentos tende a ser maior. Isso porque, a fricção imposta pela distância tende a impor custos monetários que somente quem possui maiores rendimentos pode arcar.

Tabela 8 - População residente matriculada no ensino superior, por classes de rendimentos brutos totais, segundo o local da IES e município de residência. RMBS. 2010

\begin{tabular}{|c|c|c|c|c|c|c|c|c|c|}
\hline \multirow{3}{*}{$\begin{array}{l}\text { Local da } \\
\text { IES }\end{array}$} & \multirow{3}{*}{$\begin{array}{l}\text { Município de } \\
\text { residência }\end{array}$} & \multicolumn{7}{|c|}{ Classes de rendimentos } & \multirow{3}{*}{ Total } \\
\hline & & $\begin{array}{c}\text { Até } 1 \\
\text { salário } \\
\text { mínimo }\end{array}$ & $\begin{array}{l}\text { Mais de } 1 \\
\text { até } 2 \\
\text { salários } \\
\text { mínimos }\end{array}$ & $\begin{array}{c}\text { Mais de } 2 \\
\text { até } 3 \\
\text { salários } \\
\text { mínimos }\end{array}$ & $\begin{array}{c}\text { Mais de } 3 \\
\text { até } 5 \\
\text { salários } \\
\text { mínimos }\end{array}$ & $\begin{array}{c}\text { Mais de } 5 \\
\text { até } 10 \\
\text { salários } \\
\text { mínimos }\end{array}$ & $\begin{array}{c}\text { Mais de } 10 \\
\text { até } 20 \\
\text { salários } \\
\text { mínimos }\end{array}$ & $\begin{array}{c}\text { Mais de } 20 \\
\text { salários } \\
\text { mínimos }\end{array}$ & \\
\hline & & \multicolumn{7}{|c|}{$\%$} & \\
\hline \multirow{10}{*}{$\begin{array}{c}\text { Mesmo } \\
\text { município } \\
\text { de } \\
\text { residência }\end{array}$} & BERTIOGA & 11,5 & 25,4 & 31,1 & 12,4 & 16,0 & 3,6 & 0,0 & 331 \\
\hline & CUBATÃO & 8,6 & 37,7 & 26,2 & 21,2 & 6,3 & 0,0 & 0,0 & 302 \\
\hline & GUARUJÁ & 15,5 & 47,0 & 17,5 & 11,6 & 6,1 & 1,7 & 0,5 & 3172 \\
\hline & ITANHAÉM & 17,5 & 49,9 & 22,0 & 3,9 & 5,1 & 1,5 & 0,0 & 667 \\
\hline & MONGAGUÁ & 51,8 & 35,3 & 0,0 & 12,9 & 0,0 & 0,0 & 0,0 & 85 \\
\hline & PERUIBBE & 19,7 & 42,3 & 23,2 & 11,6 & 3,2 & 0,0 & 0,0 & 310 \\
\hline & PRAIA GRANDE & 13,6 & 46,6 & 16,7 & 13,9 & 7,4 & 1,8 & 0,0 & 1860 \\
\hline & SANTOS & 12,9 & 37,0 & 17,4 & 14,1 & 11,6 & 5,3 & 1,7 & 13271 \\
\hline & SÃO VICENTE & 16,2 & 47,7 & 17,3 & 8,9 & 7,5 & 2,3 & 0,0 & 1904 \\
\hline & Total & 13,9 & 40,5 & 17,8 & 13,0 & 9,7 & 3,9 & 1,1 & 21904 \\
\hline \multirow{10}{*}{$\begin{array}{c}\text { Outro } \\
\text { município }\end{array}$} & BERTIOGA & 4,1 & 25,8 & 22,7 & 15,9 & 24,7 & 6,8 & 0,0 & 365 \\
\hline & CUBATÃO & 13,2 & 33,9 & 24,6 & 16,9 & 9,8 & 1,3 & 0,4 & 1972 \\
\hline & GUARUJÁ & 8,2 & 33,5 & 21,9 & 19,1 & 12,5 & 2,5 & 2,4 & 1829 \\
\hline & ITANHAÉM & 17,0 & 31,9 & 12,2 & 19,3 & 12,0 & 5,6 & 2,0 & 869 \\
\hline & MONGAGUÁ & 20,2 & 53,8 & 8,1 & 5,6 & 11,1 & 1,2 & 0,0 & 504 \\
\hline & PERUİBE & 17,5 & 33,3 & 9,7 & 20,2 & 11,3 & 8,1 & 0,0 & 595 \\
\hline & PRAIA GRANDE & 12,7 & 36,8 & 17,9 & 13,7 & 13,5 & 2,6 & 2,9 & 3417 \\
\hline & SANTOS & 9,9 & 19,8 & 13,3 & 21,6 & 20,5 & 10,9 & 4,0 & 2216 \\
\hline & SÃO VICENTE & 13,0 & 40,6 & 17,6 & 16,4 & 9,4 & 3,1 & 0,0 & 5135 \\
\hline & Total & 12,4 & 34,9 & 17,6 & 16,8 & 12,6 & 4,1 & 1,5 & 16900 \\
\hline
\end{tabular}

FONTE: FIBGE. Microdados da amostra do Censo Demográfico 2010. Tabulações especiais NEPO.

Um dos custos monetários que podem ser citados é o transporte, que foi avaliado na tabela 9, construída por meio dos dados da pesquisa do Projeto Vulnerabilidade. Realmente, quem se desloca para outro município opta pelo transporte público individual, mais caro (48\% e 38,5\%, respectivamente). Em alguns municípios, como Cubatão e Itanhaém, modo de deslocamento por carro responde pela totalidade dos deslocamentos. Deve-se ressaltar, o peso de São Vicente nesses números, que, em sua parte insular, é conturbado com o município de Santos, possuindo uma malha de transporte público rodoviário, integrada com o município em questão.

Em contrapartida, quem não realiza deslocamento pendular, opta por se dirigir por transporte público ou, a pé, para a IES. Não, por acaso, estes são os modos de deslocamento menos onerosos monetariamente. 
Tabela 9 - População residente matriculada no ensino superior, por modo de deslocamento, segundo o local da IES e município de residência. RMBS. 2007.

\begin{tabular}{|c|c|c|c|c|c|c|c|c|}
\hline \multirow{3}{*}{$\begin{array}{l}\text { Local da } \\
\text { IES }\end{array}$} & \multirow{3}{*}{$\begin{array}{l}\text { Município } \\
\text { de } \\
\text { Residência }\end{array}$} & \multicolumn{6}{|c|}{ Modo de deslocalmento } & \multirow{3}{*}{ Total } \\
\hline & & $\begin{array}{c}\text { Público } \\
\text { (ônibus e } \\
\text { vans) }\end{array}$ & $\begin{array}{c}\text { Individual } \\
\text { (carro) }\end{array}$ & $\begin{array}{c}\text { Fretado } \\
\text { (ônibus e } \\
\text { vans) }\end{array}$ & A pé & $\begin{array}{c}\text { De ônibus } \\
\text { da } \\
\text { prefeitura }\end{array}$ & $\begin{array}{c}\text { Individual } \\
\text { (moto) }\end{array}$ & \\
\hline & & \multicolumn{6}{|c|}{$\%$} & \\
\hline \multirow{5}{*}{$\begin{array}{l}\text { Mesmo } \\
\text { município } \\
\text { de } \\
\text { residência }\end{array}$} & Guarujá & 61,1 & 20,9 & 0,0 & 18,0 & 0,0 & 0,0 & 1586 \\
\hline & Praia Grande & 20,2 & 18,2 & 0,0 & 61,6 & 0,0 & 0,0 & 1560 \\
\hline & Santos & 36,1 & 40,6 & 0,0 & 20,3 & 0,0 & 3,0 & 15995 \\
\hline & São Vicente & 77,0 & 0,0 & 0,0 & 23,0 & 0,0 & 0,0 & 1472 \\
\hline & Total & 39,7 & 34,5 & 0,0 & 23,5 & 0,0 & 2,3 & 20613 \\
\hline \multirow{8}{*}{$\begin{array}{c}\text { Outro } \\
\text { municipio }\end{array}$} & Cubatão & 0,0 & 100,0 & 0,0 & 0,0 & 0,0 & 0,0 & 270 \\
\hline & Guarujá & 33,0 & 67,0 & 0,0 & 0,0 & 0,0 & 0,0 & 503 \\
\hline & Itanhaém & 0,0 & 100,0 & 0,0 & 0,0 & 0,0 & 0,0 & 815 \\
\hline & Mongaguá & 66,5 & 33,5 & 0,0 & 0,0 & 0,0 & 0,0 & 1010 \\
\hline & Peruibe & 67,8 & 0,0 & 32,2 & 0,0 & 0,0 & 0,0 & 948 \\
\hline & Praia Grande & 45,3 & 40,8 & 0,0 & 0,0 & 0,0 & 14,0 & 4875 \\
\hline & São Vicente & 58,5 & 23,6 & 0,0 & 0,0 & 9,9 & 8,0 & 3429 \\
\hline & Total & 48,0 & 38,5 & 2,6 & 0,0 & 2,9 & 8,1 & 11850 \\
\hline
\end{tabular}

FONTE: NEPO. Microdados da amostra da Pesquisa de Campo do Projeto Vulnerabilidade 2007. Tabulações especiais (NEPO/UNICAMP)

\section{CONSIDERAÇÕES}

A partir da discussão teórica desenvolvida e da análise dos resultados apresentados aqui observou-se que a carência e desigualdade na oferta de vagas de IES, privadas e, sobretudo, públicas, em grande parte dos municípios que compõem a RMBS, são uma das marcas principais da educação da região. Em contraponto com um mercado de trabalho relativamente amplo (sustentado pela indústria, atividades portuárias e turismo), na RMBS a proporção de pessoas que estudavam e trabalhavam, respectivamente, em municípios diferentes do que residem, é de 44,24\% e 24,82\%,

Ressalta-se, como se destacou no texto, que este contexto tem raízes históricoestruturais, que remontam o processo de reestruturação produtiva vivenciado pelo estado de São Paulo, a partir dos anos 80, que colocou a Baixada Santista a margem dos principais investimentos em pesquisa e tecnologia realizados a partir de então. Esse panorama se desdobrou na proporção de deslocamentos pendulares para fins de estudo registrados na região, relativamente alto se comparada a outras realidades metropolitanas, como São Paulo e Campinas, como também, a média verificada para o estado de São Paulo e Brasil. 
Igualmente, como efeito da desigualdade na localização da IES, verificou-se, intrarregionalmente, uma orientação centrípeta dos fluxos em direção ao core metropolitano represento pelo município de Santos que concentra a maior parte das IES (em sua maioria privadas). Concomitantemente, no âmbito interregional, observou-se uma disposição centrífuga de grande parte dos fluxos, mais precisamente, originários de municípios de fora do core metropolitano, tais como Bertioga, Itanhaém, Peruíbe e Mongaguá, em direção à RMSP, onde a oferta de IES, principalmente, públicas de qualidade é mais abrangente.

Algumas consequências sociais resultantes desses deslocamentos também foram identificadas. No âmbito individual, o tempo despendido pelos indivíduos no trajeto entre sua residência e a IES é substancialmente maior entre aqueles que realizam deslocamento pendular, com efeitos sobre sua reprodução social e econômica.

No âmbito social, foi percebida uma sensível seletividade socioeconômica entre quem faz ou não deslocamento pendular para frequentar uma IES, observando-se uma renda superior dos primeiros em relação aos últimos. Pode-se supor que a maior parte daqueles que não fazem deslocamento pendular, ou deixa de fazer por falta de recursos, com consequências patentes sobre suas possibilidades de acessar a estrutura de oportunidades metropolitana a partir de uma melhor qualificação.

Assim, considerando a dinâmica desses deslocamentos como efeito da carência de um tipo de serviço fundamental como a educação superior, em especial a pública, torna-se imprescindível apoiar-se em abordagens teóricas e analíticas capazes de superar as visões tradicionais acerca do fenômeno e que permitam um olhar mais atento para essa questão na região.

\section{REFERÊNCIAS BIBLIOGRÁFICAS}

BRANCO, M. L. G. C.; FIRKOWSKI, O. L. C. de F.; MOURA, R. Movimento pendular e perspectivas de pesquisas em aglomerados urbanos. São Paulo em Perspectiva, São Paulo, v.19, n.4, out./dez.2005

CAIADO, M. C. S. Estruturação intra-urbana na Região do Distrito Federal e entorno. Revista Brasileira de Estudos da População, São Paulo, v.22, n.1, p.55-88, jan./jun.2005

CASTELLS, M. A questão urbana. São Paulo: Paz e Terra, 1975. (Edição revisada e acompanhada de um posfácio). 
COLANTONIO, F. C. Região metropolitana da Baixada Santista: transformações recentes. Dissertação (Mestrado em Desenvolvimento Econômico).Universidade Estadual de Campinas. Campinas, 2009

COURGEAU, D. Méthodes de Mesure de la Mobilité Spatiale: Migrations internes, mobilité temporaire, navettes. Paris: Éditions de L'Institut National d'Études Démographiques, 1988. 306p

CUNHA, J. M. P. da. Mobilidade populacional e expansão urbana: o caso da Região Metropolitana de São Paulo. Campinas, 1994. 311f. Tese (Doutorado) - Instituto de Filosofia e Ciências Humanas, Universidade Estadual de Campinas.

; JAKOB, A. A. E.; JIMENEZ, M. A.; TRAD, I. L. Expansão metropolitana, mobilidade espacial e segregação nos anos 90: o caso da RM de Campinas. In: CUNHA, J. M. P. da (org). Novas Metrópoles Paulistas: população, vulnerabilidade e segregação. Campinas, 2006, p.337-363.

et al. Movimentos pendulares na MMP. Relatório de pesquisa de apoio à elaboração do Plano de Ação da Macrometrópole Paulista (PAM). NEPOUNICAMP/FUNDAP/EMPLASA. São Paulo. 2013.

DEDECCA, C.. Economia e Mercado de Trabalho. In: Dedecca, C.; Montali, L.; Baeninger, R.. Regiões Metropolitanas e Pólos Econômicos do Estado de São Paulo: desigualdades e indicadores para as Políticas Sociais/ Região Metropolitana da Baixada Santista. 2009.

FUSCO, W.; OJIMA, R. Educação e desenvolvimento regional: os efeitos indiretos da política de descentralização do ensino superior e a mobilidade pendular no estado de Pernambuco. G\&DR, v. 13, n. 1, p. 247-263, jan-abr/2017, Taubaté, SP, Brasil.

HARVEY, D. Urbanismo y desigualdad social. 6.ed. Madrid: Ed. Siglo Veintiuno, 1992.

IBGE. Instituto Brasileiro de Geografia e Estatística. Censo Demográfico de 2010. Microdados da amostra. Rio de Janeiro, 2011.

INEP. Instituto Nacional de Estudos e Pesquisas Educacionais Anísio Teixeira (INEP). Censo da Educação Superior de 2010. Rio de Janeiro, 2011.

JAKOB, A. A. E.. Análise sociodemográfica da constituição do espaço urbano da Região Metropolitana da Baixada Santista no período 1960-2000. Campinas, 2003. 220f. Tese (Doutorado em Demografia) - Instituto de Filosofia e Ciências Humanas, Universidade Estadual de Campinas.

JUN, M.; BAE, C. C. Estimating the commuting costs of seoul's greenbelt. International Regional Science Review, Philadelphia, v.23, n.3, p.300-315, 2000. Harvey (1992: 53),

LAGO, L. C. O mercado de trabalho na metrópole do Rio de Janeiro: a 'periferia' que virou 'centro. Anais do Encontro da ABEP, 2008. 
LIMA, W. de M. Novas mobilidades, espaço de vida e desempenho escolar: o caso dos estudantes de ensino médio no município de Natal - RN. Dissertação (Mestrado em Demografia) / William de Mendonça Lima. - Natal, 2015. 107 f.

MARANDOLA JR. E. J. Habitar em risco: mobilidade e vulnerabilidade na experiência metropolitana. Tese (Doutorado) - Instituto de Filosofia e Ciências Humanas, Universidade Estadual de Campinas. Campinas, SP, 2008.

MAGALHÃES, D. J. A. Vaz, BRITO, E. A. de S.; SILVA, Iara Almeida. Dinâmicas de espaços de vida urbana: padrões diários de encadeamento de atividades humanas. In: ENCONTRO NACIONAL DE ESTUDOS POPULACIONAIS, 15., 2006, Caxambu. Anais... Belo Horizonte: ABEP, 2006

NEPO. Núcleo de Estudos de População "Elza Berquó". Microdados da amostra da pesquisa de campo do projeto "Dinâmica Intrametropolitana e Vulnerabilidade nas Metrópoles do Interior Paulista: Campinas e Santos”. 2008.

PEREIRA, R. H. M. Processos socioespaciais, reestruturação urbana e deslocamentos pendulares na região metropolitana de Campinas. Instituto de Filosofia e Ciências Humanas, Universidade Estadual de Campinas. Dissertação (Mestrado), Campinas, 2008 .

SOBREIRA, D. P. A metrópole e seus deslocamentos populacionais cotidianos: o caso do deslocamento pendular na Região Metropolitana de Campinas. Campinas, 2007. Dissertação (Mestrado) - Instituto de Filosofia e Ciências Humanas, Universidade de Campinas. 